\title{
Persistent "Silent" Chlamydia trachomatis Female Genital Tract Infections
}

\author{
M. Askienazy-Elbhar ${ }^{1 *}$ and J. Henry-Suchet ${ }^{2}$ \\ ${ }^{1}$ Laboratoire de Biologie Médicale Magenta, Paris, France \\ ${ }^{2}$ C.H. Jean Rostand, Sères, France
}

KEY WORDS

Chlamydia trachomatis; infection; heat shock proteins

$\mathrm{C}$ hronic chlamydial infections have been documented in numerous works ${ }^{1,2}$ as silently evolving diseases. Evidence of resistance to antibiotic therapy, as demonstrated by positive cultures long after treatment in infertile women, ${ }^{3,4}$ as well as positive chlamydial antigens or nucleic acids in culture-negative pelvic samples of infertile women $^{5}$ and the discovery of chlamydial RNA and inflammatory cytokines transcripts in tubes ${ }^{6}$ or joints, ${ }^{7}$ have led investigators to consider persistence of the infectious material responsible for the acquisition of chronicity. So far, animal models in numerous works ${ }^{8}$ have proved the persistence of viable chlamydiae in altered cell cultures. Many authors have also associated serious sequelae of unsuspected silent infections with the genetically restricted host response to the heat shock proteins (Hsps) secreted by bacteria, especially Hsp60 and Hsp70, which correspond to the chlamydial Gro-El and DNA-K genes, ${ }^{9-12}$ suggesting that repeated or prolonged exposure to the Hsp antigens is responsible for the strong host response against these bacterial Hsps and against self-Hsps homologous to the bacterial ones. ${ }^{13}$ The consequence of the alloimmunity to chlamydial antigens and Hsps, and of the autoimmunity to self-Hsps, is persistent inflammation, scarring, fibrosis, and necrosis. The clinical long-term female diseases documented are ectopic pregnancy with altered ciliary tubal function, tubal infertility with obstructed tubes, and early embryo rejection with immune interfer- ence ${ }^{14,15}$ in women undergoing in vitro fertilization for tubal factor infertility. A normal chlamydial growth can give viable chlamydiae recovered from sick tissues of obstructed tubes without any previous notice of pelvic inflammatory disease (PID); conversely, persistent chlamydiae can produce overt infections. But, culture is almost impossible unless multiple serial passages ${ }^{16}$ are performed in most chronic cases. It is not known whether chronic chlamydial disease is a consequence of an evolving silent (asymptomatic) infection, a natural infection, or a thoroughly treated and eradicated infection.

The clinical assumption of persistent chlamydial infection in the genital tract has been reached by the observation of functional disease associated with a previous infection, documented by positive chlamydial antibodies. The infectious etiology of tubal obstruction has been assessed by several authors, most often by chlamydial antibody testing. ${ }^{17}$ However, it has never been clear whether antichlamydial immunoglobulin ( $\mathrm{Ig}) \mathrm{G}$ is only a serologic scar in the absence of specific $\operatorname{IgA}$ or $\operatorname{IgM}$, nor whether untreated cervical chlamydial infection would ascend to the upper genital tract or selfresolve, nor which infection would persist even after treatment with and evolve with the host tissue division.

The implication of Chlamydia trachomatis with mucopurulent cervicitis and plasma cell endometritis was found of $64 \%$ of asymptomatic women in

*Correspondence to: M. Askienazy-Elbhar, Laboratoire de Biologie Médicale Magenta, 41 Boulevard de Magenta, 75010 Paris, France. 
a recent work. ${ }^{18}$ Sexually transmitted pathogens like $C$. trachomatis and Neisseria gonorrhoeae play a starter role in the infection by ascending the cervix, followed by anaerobic and bacterial vaginosisassociated bacteria. Pelvic inflammatory disease and $C$. trachomatis are strongly associated. In a $C$. trachomatis-PID model, ${ }^{19}$ pro-inflammatory cytokines were induced in the cervix 20 hours after infection. Recurrent infections increase the risk for PID, and prior PID increases the risk for infertility, ${ }^{20}$ similar to the progressive scarring caused by chronic trachoma. Susceptibility for PID is genetically restricted by the human leukocyte antigen class-I antigens. ${ }^{21,22}$ A significantly higher prevalence of anti-C Hsp60 antibodies has been found in patients with occluded tubes $(90 \%)$ than in patients from a sexually transmitted disease clinic infected with C. trachomatis. ${ }^{19} \mathrm{C}$ Hsp60 induces chronic Tcell immunopathogenesis and produces autoimmune cross-reaction with human Hsp60 and immune complex formation.

Two different situations appear clearly: the invasion by the pathogen with acute inflammatory host response and the persistent infection with a chronic permanent inflammation and tissue damage. What bears evidence is the presence of chlamydial antigens, Hsps, DNA, and RNA in diseased tissue preparations, especially submucosae processed with histologic techniques. ${ }^{5}$ Those tissues are usually culture negative, though, unless in straining conditions where nutrients are carefully added by multiple passages. ${ }^{16}$ We know that Hsps are sufficient to activate $\mathrm{T}$ cells and promote $\mathrm{TH} 1$ cytokines. We also know that delayed hypersensitivity and autoimmunity to human Hsp60 induce lymphocyte and macrophage proliferation with toxic products emission that concurs with fibrosis and necrosis. Genital infection is not such a good model of persistent infection as trachoma, in which scarring and blindness can be observed. However, as with trachoma, alteration of tissues leading to functional impairment occurs after a previous infection and without any sign other than the presence of nucleic acids, membrane antigens, and stress proteins. Moreover, many works have long associated tissue scarring with permanent inflammation and delayed hypersensitivity due to autoimmunity to self-Hsps. ${ }^{23}$ Immunomodulation with tumor necrosis factor- $\alpha$ (TNF- $\alpha$ ), Hsp60 or 70, and major histocompatibility complex class-I genes makes sense when their chromosomal proximity is considered. Consistent with that assessment, mRNA for TNF- $\alpha$ and interleukins (IL) 1 and 6 has been found in tubal tissues from patients with ectopic pregnancy and tubal infertility. ${ }^{6,21}$ This finding proved that viable chlamydiae were there and were associated with inflammation. Another work even demonstrated that chlamydiae cultivated in macrophages from joint tissue of a Reiter syndrome patient infected long ago became infectious again. ${ }^{7}$

Those works demonstrated the subclinical or asymptomatic presence of chlamydiae in an incomplete, debilitated form capable of inducing inflammation and thus necrosis and fibrosis under certain conditions. From in vitro models, we could assume that "persistent" chlamydiae could be responsible for that particular physiopathology. But, they could also be the inactive witnesses of the harm already done by the active infection. However, the presence of mRNA in the tissues, and the power of neoactivation into active infection, pledge for living but quiescent material.

What do we learn from recent in vitro studies? ${ }^{8,25}$ Several factors inhibit the normal development cycle of Chlamydia: host cell cytokines (interferon- $\gamma$ with the mediation of TNF- $\alpha$ ), antibiotics like penicillin, ampicillin, and chlortetracycline. Cyclic nucleotides like cyclic adenosine monophosphate (cAMP) and deprivation of nutrients like tryptophan and cysteine impair the synthesis of the elementary bodies (EBS) membrane outer membrane proteins and thus the cell division and differentiation of the reticulate bodies (RBS) that remain large and atypical. To date such aberrant RBS have not been identified in vivo, but conditions of their presence could easily be reached in a natural infection: cytokine emission from the host, humoral anti-major outer membrane protein antibodies with a partial protective effect to the host cell, and deprived nutrient factors in deep tissues with altered cell membrane functions. Antibiotics like penicillin or ampicillin used for other infections can induce persistent forms. Tetracycline can reverse the bactericidal effect if administered at the wrong stage of the cycle. Moreover, those adverse conditions induce a progressive disappearance of the membrane proteins and an increase of stress proteins which, as in other bacteria, contribute to the loss of susceptibility to antimicrobial 
agents. This observation is consistent with the clinical inadequacy of classical treatments in chronic infections. However, we do not know whether this decreased susceptibility is due to the antimicrobial itself or to the alterations of the membrane.

\section{CONCLUSION}

Are silent genital chlamydial infections due to persistent forms of Chlamydia? The nucleic acids, Hsps, and antigens recognized in diseased tissues that are culture negative for Chlamydia are sufficient proof of immune stimulation and chronic active disease. Persistent forms are admitted as stress response forms capable of living again under favorable circumstances. Removal of factors inducing persistence can reactivate resolved infections under immunosuppressive conditions: coinfection with $N$. gonorrhoeae or environmental factors like hormones or vaginal flora. But, the consequence of a blocked development cycle does not offer a possibility of chemotherapy for these infections. Persistent abnormal forms must be recognized in vivo before the clinical features of silent infections can be assimilated to the cell-culture model of persistent chlamydiae. Persistence, thus chronic disease, might not occur after a well-treated uncomplicated cervical infection. It is therefore important to recognize the risk for chronicity at the onset of an infection. Anti- major outer membrane protein and anti-lipopolysaccharide antibodies could go undetected in a chronic infection, so anti-C Hsp60 antibodies should be routinely processed when a chronic infection is suspected in cases of tubal infertility or when in vitro fertilization fails. Treatment of persistent silent diseases and resolution of chronic infection should be improved by more knowledge of persistent infection.

\section{REFERENCES}

1. Lehtinen M, Paavonen J. Heat shock proteins in the immunopathogenesis of chlamydial pelvic inflammatory disease. Proceedings of the 8th International Symposium on Human Chlamydial Infections, Orfila J, Byrne G, Chernesky MA, et al (eds). Monvillargeney, France, 1994, p 599-610.

2. Henry-Suchet J, Utzmann C, De Brux J, et al. Microbiologic study of chronic inflammation associated with tubal factor infertility: Role of Chlamydia trachomatis. Fertil Steril 1987;47:274-277.

3. Henry-Suchet J, Askienazy-Elbhar M, Thibon M, et al. Post therapeutic evolution of serum chlamydial anti- body titers in women with acute salpingitis and tubal infertility. Fertil Steril 1994;62:296-304.

4. Kiviat NB, Wolner-Hanssen, Peterson M, et al. Localization of Chlamydia trachomatis infection by direct immunofluorescence and culture in pelvic inflammatory disease. Am J Obstet Gynecol 1986;154:865-873.

5. Patton DL, Askienazy-Elbhar M, Henry-Suchet J, et al. Detection of Chlamydia trachomatis in fallopian tube tissue in women with postinfectious tubal infertility. Am J Obstet Gynecol 1994;171:95-101.

6. Patton DL. Immune responses to $C$. trachomatis infections in a non human primate model. Infect Dis Obstet Gynecol 1996;4:159-162.

7. Köhler L, Nettelnbreker E, Zeidler H, et al. Persistence of Chlamydia trachomatis serovar $\mathrm{K}$ in a non culturable but metabolically active state in human peripheral blood monocytes. Proceedings of the 3rd meeting of the European Society for Chlamydia Research, Stary (ed.), 1996;3:331.

8. Beatty WL, Morrison RP, Byrne GI. Persistent chlamydiae: From cell culture to a paradigm for chlamydial pathogenesis. Microbiol Rev 1994;58:686-699.

9. Brunham RC, MacLean IW, Binns B, et al. Chlamydia trachomatis: its role in tubal infertility. J Infect Dis 1985; 152:1275-1282.

10. Morrison RP, Lyng K, Caldwell HD. Chlamydial disease pathogenesis. Ocular hypersensitivity elicited by a genus specific 57 kD protein. J Exp Med 1989;169:663675.

11. Witkin SS, Jeremias J, Toth M, et al. Cell mediated immune response to the recombinant $57 \mathrm{kDa}$ heat shock protein of Chlamydia trachomatis in women with salpingitis. J Infect Dis 1993;167:1379-1383.

12. Arno JN, Yuan Y, Cleary RE, et al. Serologic responses of infertile women to the $60 \mathrm{kD}$ chlamydial heat shock protein (hsp 60). Fertil Steril 1995;64:730-735.

13. Morrison RP, Manning DS, Caldwell HD. Immunology of Chlamydia trachomatis infections. Immunoprotective and immunopathogenetic responses. In: Quinn TC (ed): Sexually Transmitted Diseases. New York: Raven Press, 1992, p 57-84.

14. Witkin SS, Sultan KM, Neal GS, et al. Unsuspected chlamydial infection and in vitro fertilization outcome. Am J Obstet Gynecol 1994;171:1208-1214.

15. Askienazy-Elbhar M. Immune consequences of chlamydial infections in pregnancy and in vitro fertilization outcome. Infect Dis Obstet Gynecol 1996;4:143-148.

16. Askienazy-Elbhar M, Moncan T, Orfila J, et al. Cultures de prélèvements pelviens dans des chlamydioses aigües ou chroniques. Etude des sérotypes obtenus. Proceedings of the 6th International Symposium on Sexually Transmitted Diseases Research meeting, Banff, Canada, 1991.

17. Toye B, Laferrière C, Claman $\mathrm{P}$, et al. Association between the chlamydial heat shock protein and tubal infertility. J Infect Dis 1993;168:1236-1240. 
18. Paavonen J. Pelvic inflammatory disease: A global medical emergency. Proceedings of the 12th International Symposium on Sexually Transmitted Diseases Research meeting, Seville, Spain, 1997.

19. Stamm WE. Pathogenesis of pelvic inflammatory disease. Proceedings of the 12th International Symposium on Sexually Transmitted Diseases Research meeting, Seville, Spain, 1997.

20. Patton DL, Kuo CC, Wang SP, et al. Distal tubal obstruction induced by repeated Chlamydia trachomatis salpingeal infections in pig-tailed macaques. J Infect Dis 1987;155:1292-1299.

21. Lichtenwalner AB, Patton DL, Cosgrove SJ, et al. MHC Class-I alleles associated with relative susceptibility to pelvic inflammatory disease in Chlamydia trachomatisinfected macaques. Proceedings of the 3rd meeting of the European Society for Chlamydia Research, Stary ed., 1996;3:104.

22. Morrison RP. Immune protection against Chlamydia trachomatis in females. Infect Dis Obstet Gynecol 1996;4: 163-170.

23. Schachter J. Chlamydial infections. N Engl J Med 1978; 298:428-435.

24. Gerard HC, Branigan PJ, Minassian SS, et al. Viability of inapparent Chlamydia trachomatis in fallopian tubes of ectopic pregnancies. Proceedings of the 3rd meeting of the European Society for Chlamydia Research, Stary (ed.), 1996;3:296.

25. Beatty WL, Byrne GI, Morrison RP. Repeated and persistent infection with Chlamydia and the development of chronic inflammation and disease. Trends Microbiol 1994;95:2;3. 


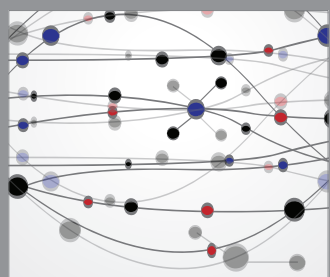

The Scientific World Journal
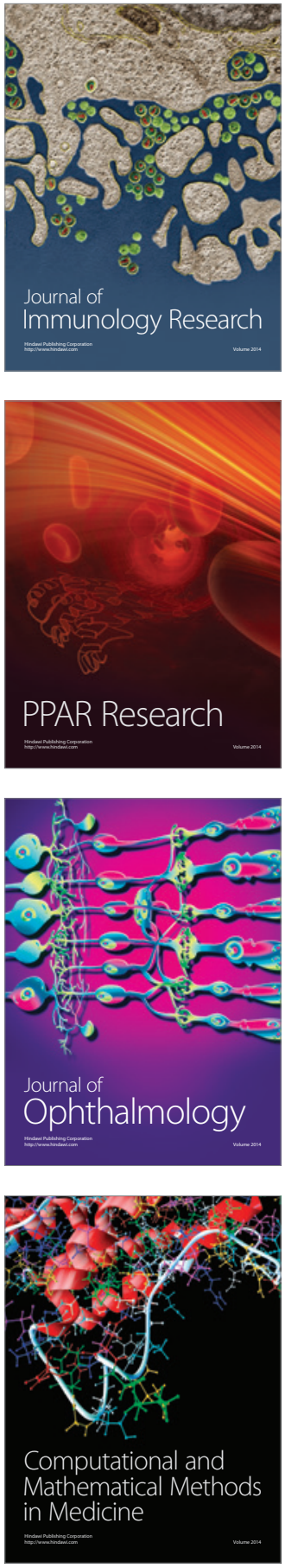

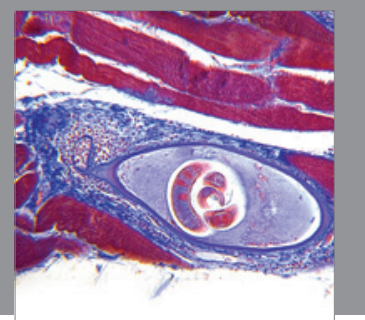

Gastroenterology

Research and Practice
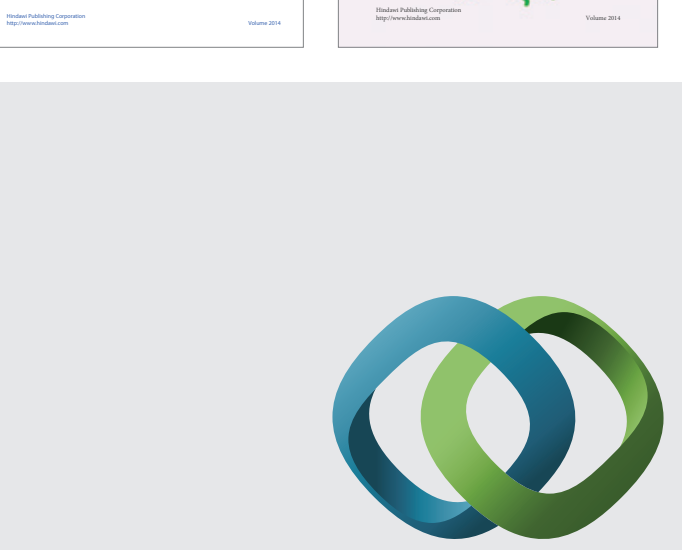

\section{Hindawi}

Submit your manuscripts at

http://www.hindawi.com
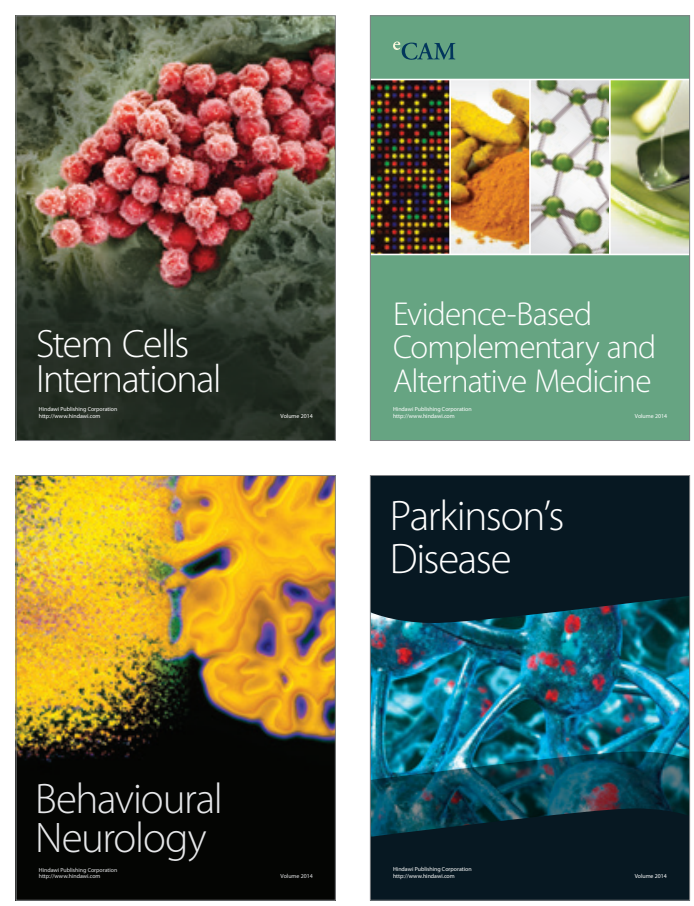

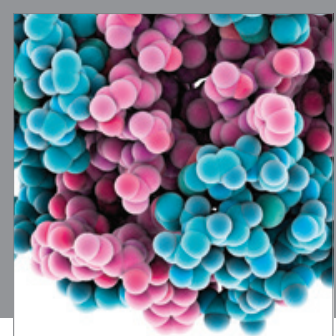

Journal of
Diabetes Research

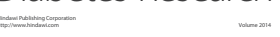

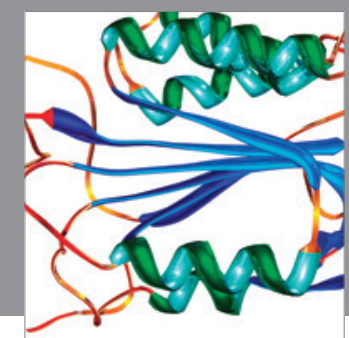

Disease Markers
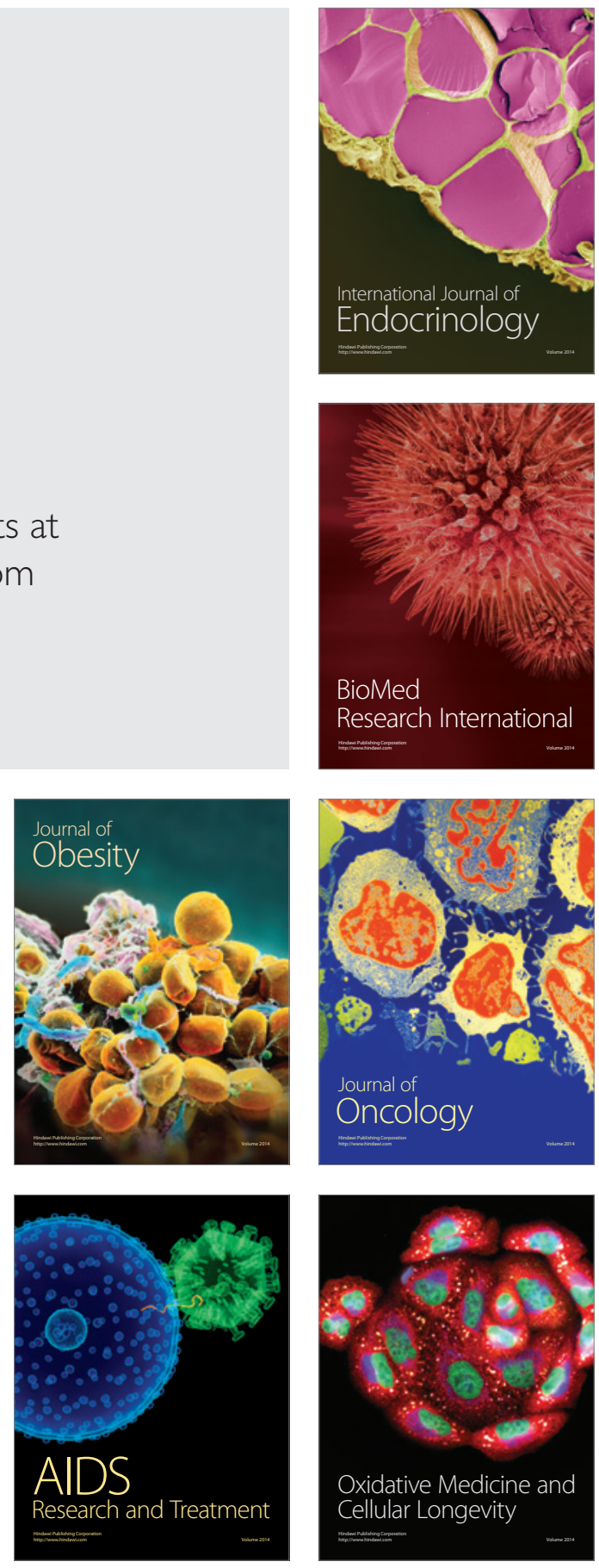